\title{
Evaluating a Donor-Funded Reproductive Rights Experiential Learning Program
}

Clare Daniel, Tulane University

APSA TLC 2020

\begin{abstract}
:
This paper will discuss the characteristics, learning objectives, challenges, and outcomes of a donor-funded internship program for undergraduate students interested in reproductive rights, health, and justice at Tulane University's Newcomb Institute. I argue that this model, while it has unique challenges, is well-suited to meet the objectives typically established for service-learning programs, including the development of authentic, mutually beneficial, sustainable relationships between community partners and the university (James and Logan 17) and the cultivation of students' senses of self-efficacy and interest in community engagement (Knapp et al.).
\end{abstract}




\section{Introduction:}

Public service is an important part of Tulane University's institutional identity and undergraduate core curriculum. In the wake of Hurricane Katrina, Tulane reinvented itself as a community-engaged, service-oriented university working to recover and reinvigorate a devastated city (Giegerich). Tulane became the first major university to require service-learning as part of its core curriculum. The university requires two separate service-learning experiences over the course of the undergraduate years, one that is incorporated into a course (20 or 40 hours of service) and one that can either be part of a course or an internship for academic credit. These service-learning experiences are administered by the Center for Public Service, whose vision is “to promote community, equality, and justice" (Center for Public Service).

In general, service-learning experiences are meant develop authentic, mutually beneficial, sustainable relationships between community partners and the university (James and Logan 17) and cultivate students' senses of self-efficacy and interest in community engagement (Knapp et al.). Although the Center for Public Service at Tulane works hard to ensure quality servicelearning experiences for students and community partners and is at the forefront of this work nationally, there are many critiques of this requirement that remain important and relevant. For instance, some argue that, without the proper time, training, and resources, which can be difficult to access within the course of one semester, service-learning places a burden on the community organizations it is meant to help (Strom; Eby). Others suggest that perhaps it is more akin to "voluntourism," in which students use their brief time working with disadvantaged communities to experience personal transformation while providing no real benefit to those communities (Dobson). Still others point to the ways that service-learning often reifies, rather than dismantles, the structures and logics of white privilege and supremacy (Mitchell, et al.) 
These critiques of service-learning make up just one facet of the relationship between Tulane University and the larger New Orleans community - a relationship that could easily be characterized as fraught. This paper explores the outcomes of a unique, donor-funded internship program focusing on community engagement around reproductive rights, health, and justice at Tulane University. It argues that such a program provides a model to overcome many of these critiques while meeting the educational goals put forth by most service-learning programs, contributing meaningfully to the missions and work of community organizations, and strengthening the relationship between the university and its surrounding community.

\section{Overview of Program:}

The Reproductive Rights and Reproductive Health Internship Program, supported by the Donna and Richard Esteves Fund for Reproductive Rights and Reproductive Health, places students in paid internships at various reproductive rights, health, and justice organizations throughout New Orleans, Louisiana. Utilizing a cohort model aimed at cultivating a "critical community" (Mitchell and Rostbank 3-4), all interns come together for biweekly meetings throughout their internship term. The program is designed to accomplish a number of interrelated goals pertaining students' career readiness, their knowledge of reproductive rights, health, and justice, and their understanding of and ability to navigate and affect political processes.

The program combines onsite professional work experience with a classroom-esque educational experience in which the cohort is able to network with and learn from each other, as well as hear from other community organizations working on issues related to reproductive rights, health, and justice. These meetings aid in the development of what Novak et al. refer to as "the ability to reframe complex social issues," which is a common objective of service-learning programs (Novak et al.). Through these meetings and their experiences at their internship sites, 
students cultivate a critical understanding of systemic injustice as they are able to map the connections between economic, environmental, racial, and reproductive justice. The program also requires students to develop professional communication skills as they present themselves and their work to the public via blog posts and poster presentations.

Another crucial aim of the program is to support and augment the reproductive rights/health/justice work of partner organizations. Louisiana is particularly challenged when it comes to reproductive health outcomes. For instance, Louisiana had the second highest rate of new chlamydia cases, seventh highest rate for syphilis, and the fifth highest rate for gonorrhea in 2018 (Centers for Disease Control and Prevention). It has one of the highest rates of maternal mortality and its rate is increasing faster than the national rate (Louisiana Department of Health). The state also has the sixth highest rate of adolescent pregnancy in the nation (Health and Human Services). At the same time, Louisiana has some of the most restrictive laws regarding sex education, abortion access, and other reproductive healthcare issues. This internship program is leverages student energy and ingenuity toward meeting these challenges.

Currently in its third year, it is also notable that the program has consistently attracted a student population that has a greater percentage of Louisiana residents and is far more racially and ethnically diverse than the overall undergraduate student body at Tulane University.1 In this way, the program is able resist and prevent the politics of whiteness mentioned above in which primarily white students presume that they have the ability to help communities of which they have little knowledge and to which they have no ties (Mitchell et al.). It provides meaningful opportunities to students who are otherwise underserved at the university, helping connect them,

\footnotetext{
${ }^{1}$ In the spring 2020 cohort, ten of the 14 interns identify as students of color $(71.4 \%)$, seven of the 14 identify as Black or African American (50\%), while five of the 14 are from Louisiana (35.7\%). The first-year class at Tulane for the $2019-2020$ academic year is $69.52 \%$ white and $9 \%$ from Louisiana (Tulane Registrar). The City of New Orleans is 59.7\% Black or African American, 33.99\% white, 5.5\% Hispanic, and 2.9\% Asian (US Census).
} 
or keep them connected, to local community while compensating them for their labor, meaning that students are able to spend more time at their site and develop a deeper mutually beneficial relationship. Additionally, the program's ability to attract students of color and students from Louisiana helps retain partnerships with organizations that are looking for students who have insight about and affinity with the populations they serve.2

\section{Student Learning Objectives:}

The program has nine clearly defined student learning objectives that guided the creation of end-of-term student and site supervisor questionnaires. The learning objectives of the program are as follows.

Students will:

1) Learn more about their identified career interests in reproductive rights, health, and/or justice by engaging with them in a professional context and executing a set of tasks associated with that career.

2) Increase their understanding of their own preferences and abilities relating to professional work settings and tasks, as they develop professional goals, reflect upon those goals, and reassess them at the end of the internship.

3) Become better prepared for their post-graduation career by gaining experience as paid workers in a professional environment. They will hone their punctuality, time management, professional correspondence practices, accountability, and other important workplace qualities, while gaining familiarity with receiving and incorporating feedback from supervisors and other stakeholders, as well as advocating for themselves in the workplace.

\footnotetext{
${ }^{2}$ I have learned this through conversations with internship partners.
} 
4) Become self-aware, self-monitoring, and self-correcting (i.e. knowing what they need to do, demonstrating initiative, completing tasks in a timely manner, working at a pace they can sustain, producing a high-quality work product, taking ownership of mistakes, and managing self-doubt, negative emotions, or frustration)

5) Develop networking and relationship-building skills through interactions with their supervisor, program coordinator, fellow interns, and community partners. They will know how to listen actively and ask engaged questions. Students will gain knowledge of the importance of professional networking.

6) Learn to present themselves and communicate their work in a professional manner in multiple public forums. They will learn how to speak clearly and concisely about their experiences and the importance of their work.

7) Develop knowledge about the landscape of reproductive rights/health/justice/politics in the United States, Louisiana, and New Orleans. They will understand what organizations exist in New Orleans and what work they do. They will gain knowledge of which issues are most pressing on the local, state, and national level and what pieces of legislation could or do govern these issues.

8) Increase their understanding of the complex interlinking of social inequalities (according to race, class, gender, sexuality, ability, etc.) and develop their senses of social justice and empathy toward marginalized communities.

9) Further their understanding of how to engage with institutions and systems of power (i.e. the local and state government, dominant discourse, etc.) to create change around reproductive issues. 
At the beginning of each term, students are asked to work with their supervisor to establish five learning goals for the internship term. They are provided with resources to help them develop S.M.A.R.T. goals (specific, measurable, achievable, relevant, time-based). Students turn these goals in to the program coordinator, they revisit these goals in the biweekly interns' meetings, and are asked to consider whether they met their goals in the program evaluation.

\section{Student Evaluation Methods and Results:}

In order to assess the effectiveness of the program in meeting these nine learning objectives, the program coordinator developed a program evaluation, which has been emailed to all interns at the end of each internship term since the end of Fall 2017. Some students participated in the program over multiple terms and were emailed a new evaluation at the end of each term. For each term, the response rates were as follows:

$100 \%$ (7 out of 7) for Fall 2017

$25 \%$ (3 out of 12) for Spring 2018

$85.7 \%$ (6 out of 7) for Summer 2018

100\% (11 out of 11) for Fall 2018

100\% (11 out of 11) for Spring 2019

$75 \%$ (9 out of 12) for Summer 2019

Over the course of these six terms, the evaluation yielded a total of 47 responses. Out of these responses, $95.7 \%$ (45 out of 47) said that the internship helped clarify their career goals (Learning Objective 1). 97.9\% (46 out of 47) said they met some or all of their five learning goals. $29.8 \%$ (14 out of 47) said that they met all of their five learning goals for the term (Learning Objective 2). 
One hundred percent of respondents stated that the internship experience increased their understanding of expectations of them in a professional work setting/arrangement, and/or increased their ability to follow the protocols of professional communication (in-person, over email, phone, social media, etc.), and/or increased their punctuality, and/or increased their ability to manage a project and produce a quality product (Learning Objective 3).

One hundred percent of respondents stated that the experience increased their ability to demonstrate initiative (i.e. identify problems and find solutions), and/or increased their ability to set their own work pace and meet deadlines and/or increased their ability to take ownership over mistakes, and/or increased their ability to incorporate constructive feedback, and/or increased their ability to manage self-doubt, negative emotions, and frustration, and/or increased their ability to advocate for themselves in the workplace (Learning Objective 4).

When asked if the internship experience helped students build their knowledge of the importance of networking and/or how to cultivate a professional relationship through mutual support, courteous communication, and follow-up 93.6\% (44 out of 47) said yes (Learning Objective 5). $87.2 \%$ (41 out of 47) said that it increased their active listening skills, and/or their ability to ask engaged questions of potential network members (Learning Objective 5).

When asked if the internship helped students practice presenting themselves and their work to the public, $97.9 \%$ (46 out of 47) said it helped through one or more of the following: blog posts they wrote about their about their work, activities they did at their internship (tabling, workshop facilitation, etc.), participation in a formal presentation at a conference or professional event (Learning Objective 6).

When asked what students learned about reproductive rights and/or health, $100 \%$ responded that they either learned about the landscape of organizations working on reproductive 
rights and health in New Orleans or that they learned about how the landscape of reproductive rights and health in Louisiana compares to that of the rest of the nation and/or the world, or both (Learning Objective 7). 95.7\% (45 out of 47) said that they either learned how the politics of race, class, gender, sexuality, ability, and immigration status intersect to affect access to reproductive rights and reproductive health services, or that they learned about the differences and similarities between the terms "reproductive rights," "reproductive health," and "reproductive justice," and their historical and social origins, or both (Learning Objective 8). $87.2 \%$ (41 out of 47) said that they either learned about strategies for for addressing unequal access to reproductive rights and healthcare services, strategies for effecting policy change, or strategies for effecting culture shift (i.e. intervening into dominant discourses that stigmatize certain sexual and reproductive behaviors), or some combination of those (Learning Objective 9).

In the site supervisor evaluations (described in detail below), supervisors were asked whether their intern(s) made progress on their five learning goals. 79\% (19 out of 24) answered "very much," while the remaining 5 respondents answered "somewhat." While student and supervisor evaluations are not anonymous, students are also given the opportunity to submit anonymous feedback about the program via a separate survey. Over the course of the six terms it has been administered, this survey has only yielded two responses. One response from Fall 2017 stated that she wished students would participate more in biweekly meetings discussions. The other, from Spring 2019, stated that the program should ensure that site supervisors are more available to provide guidance to interns.

\section{Objectives for Internship Sites:}

The primary objectives for internship sites are the following: 
1) That the intern's work contributes meaningfully to the organization's mission and benefits the organization.

2) The supervisor has a positive experience, such that she would recommend the program to colleagues and community partners.

\section{Site Supervisor Questionnaire Results:}

In order to assess the effectiveness of the program in meeting the objectives for the internship sites, in the summer of 2018, the program coordinator developed a site supervisor questionnaire, which is emailed to each site supervisor at the end of the internship term.

Conducted in this way, the questionnaire evaluated a site supervisor's experience in each term, whether she acquired a new intern or continued with the previous one. Thus, some of the responses were completed by the same person over the course of four terms (Summer 2018, Fall 2018, Spring 2019, and Summer 2019) if a supervisor remained as a participating partner for the entire duration. Over these four terms, the questionnaire response rates were as follows (with two caveats: 1 - these rates exclude the program coordinator, who is also a site supervisor, but abstains from taking questionnaire, and 2 - some supervisors had more than one intern per term and filled out one questionnaire per intern, while others who had more than one only completed one questionnaire. Each questionnaire completed was counted as 1, regardless of how many interns it evaluated.):

$71 \%$ (5 out of 7) for Summer 2018

$60 \%$ (6 out of 10) for Fall 2018

66\% (6 out of 9) for Spring 2019

87.5\% (7 out of 8) for Summer 2019 
Over the course of these four terms, the questionnaire yielded a total of 24 responses. Of these 24 responses, $21(87.5 \%)$ chose to rate their overall experience with the RRRH program as "Excellent," 1 chose "Good" (4\%), and 2 (8\%) chose "Average." Similarly, when asked if they would recommend this program to others, 21 chose "Yes, without hesitation," while 1 chose "Probably," and 2 chose "Maybe."

Perhaps most importantly, site supervisors responded to the question of how much the intern's work benefited their organization and 18 (75\%) chose "Greatly," 4 (16.7\%) chose "Somewhat," 1 (4\%) chose "Very little," and 1 did not choose an option, but stated that the intern "developed many resources for our policy education programs and assisted in updating our website with youth friendly language."

Overall, these results confirm that the program is effective at meeting its stated goals in relation to the internship sites. The few experiences documented in these evaluations that were subpar will be explained further in the next section on program challenges.

\section{Program Challenges:}

Despite these positive evaluations, this unique program presents some specific challenges, the first of which is related to donor-relations and fundraising. We received a fiveyear pledge of $\$ 75,000$ per year. We are in the fourth year and are unsure whether we will be able to continue the program at the end of the fifth year. Thus, donor stewardship and fundraising efforts have been part of coordinator's work since the program's inception.

The second and third challenges would likely also exist in any experiential learning or service-learning program that involved a university, students, and a community partner. These include clear communication between students, internship sites, and the program coordinator, and student follow-through on some of the administrative requirements of the program. 


\section{Conclusion:}

While results indicate that the program is meeting its objectives and providing a more than satisfactory experience for students and internship sites, challenges have nonetheless arisen related to 1) clear communication with and between students and internship sites, 2) student follow-through on some of the administrative requirements of the program, 3) donor relations and fundraising. Despite these challenges, it is clear that in contrast to shorter, unpaid, servicelearning experiences such as those required within Tulane's core curriculum, a donor-funded paid internship program of this sort is a crucial vehicle for the kind of deep and sustained engagement with social justice work in their surrounding communities that students particularly economically marginalized students whose time must spent in gainful employment need and desire, and which position the university as a valuable community ally. Further research into alumni outcomes would help to shed more light on the efficacy of this program in meeting some of its objectives. 


\section{Works Cited}

Centers for Disease Control and Prevention. "2018 STD Surveillance Report: State Ranking Tables," https://www.cdc.gov/std/stats18/2018-Surveillance-Report-EMBARGOEDFINAL-State-Ranking-Tables.pdf

Center for Public Service. Tulane University. https://cps.tulane.edu/about

Dobson, Shea. "Tulane Students Must Be Critical of No. 1 Peace Corps Volunteer Ranking." The Hullabaloo. September 26, 2018. https://tulanehullabaloo.com/43402/views/tulanestudents-must-be-critical-of-no-1-peace-corps-volunteer-ranking/

Eby, John. "Why Service-Learning is Bad.” Service-Learning, General. Paper 27. 1998. https://pdfs.semanticscholar.org/2448/2d903dd59eace6d42db67138cdd1d54c2944.pdf

Giegerich, Elizabeth. “A Look at Tulane University’s Service-Learning Post-Katrina.” The Nation. August 25, 2008. https://www.thenation.com/article/look-tulane-universitysservice-learning-post-katrina/

James, J. H. and K. Logan. "Documenting the Community Impact of Service-Learning Coursework: Theoretical and Practical Considerations." Partnerships: A Journal of Service-Learning and Civic Engagement, vol. 7, no 2, 2016.

Health and Human Services. "Louisiana Adolescent Reproductive Health Facts." https://www.hhs.gov/ash/oah/facts-and-stats/national-and-state-data-sheets/adolescentreproductive-health/louisiana/index.html

Knapp, T., B. Fisher, and C. Levesque-Bristol. 2010. "Service-Learning's Impact on College Students' Commitment to Future Civic Engagement, Self-Efficacy, and Social Empowerment." Journal of Community Practice 18 (2-3): 233-251. 
Louisiana Department of Health. "2011-2016 Maternal Mortality Report.” http://ldh.la.gov/assets/oph/Center-PHCH/Center-PH/maternal/20112016_MMR_Report_FINAL.pdf

Tania D. Mitchell , David M. Donahue \& Courtney Young-Law (2012) Service Learning as a Pedagogy of Whiteness, Equity \& Excellence in Education, 45:4, 612-629, https://www.tandfonline.com/doi/pdf/10.1080/10665684.2012.715534

Mitchell, T. D. and C. Rost-Banik. Service-learning cohorts as critical communities, Educational Studies, 2019.

Julie M. Novak, Vern Markey \& Mike Allen (2007) Evaluating Cognitive Outcomes of Service Learning in Higher Education: A Meta-Analysis, Communication Research Reports, 24:2, 149-157, DOI: 10.1080/08824090701304881

Strom, Stephanie. "Does Service Learning Really Help?" New York Times, 3 Jan. 2010, p. 26(L). Gale In Context: Biography, https://link.gale.com/apps/doc/A215652447/BIC?u=tulane\&sid=BIC\&xid=c0ffd396. Accessed 10 Jan. 2020.

Tulane University Office of the Registrar. “Freshman Profile: Fall 2019.” 2019. https://registrar.tulane.edu/sites/registrar.tulane.edu/files/FTF_PROFILE_2019.pdf United States Census Bureau. "Quick Facts: New Orleans city, Louisiana." https://www.census.gov/quickfacts/neworleanscitylouisiana 